\title{
Optimised biogas production from the co-digestion of sugar beet with pig slurry: Integrating energy, GHG and economic accounting
}

Boldrin, Alessio; Baral, Khagendra Raj; Fitamo, Temesgen Mathewos; Vazifehkhoran, Ali Heidarzadeh; Jensen, Ida Græsted; Kjærgaard, Ida; Lyng, Kari Anne; van Nguyen, Quan; Nielsen, Lise Skovsgaard; Triolo, Jin Mi

Published in:

Energy

Link to article, DOI:

10.1016/j.energy.2016.06.068

Publication date:

2016

Document Version

Peer reviewed version

Link back to DTU Orbit

Citation $(A P A)$ :

Boldrin, A., Baral, K. R., Fitamo, T. M., Vazifehkhoran, A. H., Jensen, I. G., Kjærgaard, I., Lyng, K. A., van Nguyen, Q., Nielsen, L. S., \& Triolo, J. M. (2016). Optimised biogas production from the co-digestion of sugar beet with pig slurry: Integrating energy, GHG and economic accounting. Energy, 112, 606-617. https://doi.org/10.1016/j.energy.2016.06.068

- You may freely distribute the URL identifying the publication in the public portal 


\title{
Optimised biogas production from the co-digestion of sugar beet with pig slurry: integrating energy, GHG and economic accounting
}

\author{
Alessio Boldrin ${ }^{1, *}$, Khagendra Raj Baral ${ }^{2}$, Temesgen Fitamo ${ }^{1}$, Ali Heidarzadeh Vazifehkhoran ${ }^{3}$, Ida \\ Græsted Jensen ${ }^{4}$, Ida Kjærgaard ${ }^{5}$, Kari-Anne Lyng ${ }^{6}$, Quan Van Nguyen ${ }^{7}$, Lise Skovsgaard Nielsen ${ }^{4}$, and Jin Mi \\ Triolo $^{3}$
}

${ }^{1}$ Department of Environmental Engineering, Technical University of Denmark, Miljoevej, 2800 Kgs. Lyngby, Denmark; aleb@env.dtu.dk (Alessio Boldrin); tefi@env.dtu.dk (Temesgen Fitamo)

${ }^{2}$ Department of Agroecology - Soil Fertility, Aarhus University, Blichers Allé 20, 8830 Tjele, Denmark; khagendra.baral@agro.au.dk (Khagendra Raj Baral)

${ }^{3}$ Biotechnology and Environmental Engineering, Institute of Chemical Engineering, Biotechnology and Environmental Technology, Faculty of Engineering, University of Southern Denmark, Campusvej 55, , Odense M 5230, Denmark; ahva@kbm.sdu.dk (Ali Heidarzadeh Vazifehkhoran); jmt@kbm.sdu.dk (Jin Mi Triolo)

${ }^{4}$ Department of Management Engineering, Technical University of Denmark, Frederiksborgvej 399, 4000 Roskilde, Denmark; idje@dtu.dk (Ida Græsted Jensen); Iskn@dtu.dk (Lise Skovsgaard Nielsen)

${ }^{5}$ Knowledge Centre for Agriculture, Agro Food Park 15, 8200 Aarhus, Denmark; ida_kj@live.dk (Ida Kjærgaard)

${ }^{6}$ Ostfold Research, Stadion 4, 1671 Kråkerøy, Norway; kari-anne@ostfoldforskning.no (Kari-Anne Lyng)

${ }^{7}$ Department of Plant and Environmental Sciences, University of Copenhagen, Thorvaldsensvej 40, 1871 Frederiksberg, Denmark; nguyen@plen.ku.dk (Quan Van Nguyen)

"NOTE: this is the author's version of a work that was accepted for publication in Energy journal. Changes resulting from the publishing process, such as peer review, editing, corrections, structural formatting, and other quality control mechanisms may not be reflected in this document. Minor changes may have been made to this manuscript since it was accepted for publication.

A definitive version is published in Energy 112, 606-617, doi: dx.doi.org/10.1016/j.energy.2016.06.068" 


\begin{abstract}
Several countries have established a number of increased targets for energy production from renewable sources. Biogas production, which will play a key role in future energy systems largely based on renewable sources, is expected to grow significantly in the next few decades. To achieve these ambitious targets, the biogas production chain has to be optimised to obtain economic viability and environmental sustainability while making use of a diversified range of feedstock materials, including agricultural residues, agro-industrial residues and, to some extent, dedicated energy crops. In this study, we integrated energetic, GHG and economic analysis to optimise biogas production from the co-digestion of pig slurry (PS) and sugar beet pulp silage (SB). We found that utilising SB as a co-substrate improves the energy and GHG balances, mostly because of increased energy production. However, utilising SB negatively affects the profitability of biogas production, because of the increased costs involved in feedstock supply. The scale of the processing plant is neutral in terms of profitability when SB is added. The results indicate that medium- to large-sized biogas plants, using low shares of SB co-substrate, may be the preferred solution.
\end{abstract}

Keywords: mass balance, value chain analysis, economy of scale, silage, transport costs.

\author{
Abbreviations: \\ AD: anaerobic digestion \\ BMP: biochemical methane potential \\ CHP: combined heat and power \\ CSTR: continuous stirred tank reactor \\ EF: emission factor \\ GHG: greenhouse gases \\ HRT: hydraulic retention time \\ PS: pig slurry \\ SB: sugar beet pulp silage \\ TC: total cost \\ TI: total income \\ TNI: total net income \\ TS: total solids \\ VS: volatile solids \\ $V_{S_{D}}$ : degradable volatile solids \\ VS$_{\mathrm{ND}}$ : non-degradable volatile solids \\ ww: wet weight
}




\section{Introduction}

Anaerobic digestion (AD) is one of the most efficient technologies for extracting clean and renewable energy from biomass with high water content [1]. In addition, $A D$ is useful for recycling nitrogen $(N)$ and phosphorus (P) from animal manure, which is in great need worldwide [2,3], and it is also considered to be the most effective technology for reducing greenhouse gas (GHG) emissions from manure management and at a low cost $[4,5]$. AD is fully integrated into Denmark's long-term strategy to be independent of fossil fuels before $2050[6,7]$. In accordance with this strategy, 50\% of all animal slurry must be used in AD by $2020[8]$, and $60 \%$ of organic waste from public services (up from the current level of $17 \%$ ) will be collected and utilised for biogas production by 2018 [9]. In 2050, biogas plants are expected to be processing about 42 PJ of biomass, corresponding to $>7 \%$ of all energy input for Denmark, while $16-22 \%$ of all biomass will be routed to energy production [10].

The AD of animal manure is in focus for two reasons: 1) large amounts of manure are available in Denmark [11] and 2) it allows for the better management of $\mathrm{N}$ and $\mathrm{P}$ nutrients at the regional level. In Denmark, manure is currently collected in the form of slurry, with a water content of about $95 \%$ and an organic matter content of ca. 4\% [12]. Owing to this high water content, manure can only be used at the present time for biogas production, though hydrothermal liquefaction may represent an alternative to anaerobic biogas production in the future. Manure has a low biogas production potential [13], meaning that its digestion needs to be boosted by a more energetic co-substrate [14]. Suitable co-substrates include other agricultural residues, organic industrial by-products (e.g. from the food industry) and dedicated bioenergy crops.

The amounts of biogas to be produced and the portfolio of biomass materials to be used represent important logistical and management challenges, the combination of which hinders environmentally sustainable and economic viable biogas production in the country. Environmental and energetic issues related to biogas production are depicted rather comprehensively in the available literature, focusing for example on the digestion and/or co-digestion of manure (e.g. Hamelin et al. [15]; De Vries et al. [16]; Lansche \& Mueller [17]), municipal organic waste (e.g. Møller et al. [18]; Bernstad et al. [19]; Boldrin et al. [20]; Levis \& Barlaz [21]), industrial co-products (e.g. Berglund \& Börjesson [22]; Tufvesson et al. [23]), sewage sludge (e.g Tarantini et al. [24]; Lederer \& Rechberger [25]; Nakakubo et al. [26]), energy crops and/or cropping systems (Amon et al. [27]; Gerin et al. [28]; Jury et al. [29]; Schumacher et al. [30]; Blengini et al. [31]; Buratti et al. [32]; González-García et al. [33]). These studies indicate that biogas production from residual biomass is generally environmentally beneficial, but the modelling of biogas from energy crops somehow seems more complex, as it must consider carefully local conditions regarding crop cultivation and the supply chain [34]. The economic viability and optimisation of biogas production has also been investigated in a number of studies (e.g. Walla \& Schneeberger [35]; Power \& Murphy [36]; Gebrezgabher et al. [37]; Karellas et al. [38]; Stürmer et al. [39]; Brown et al. [40]; Delzeit \& Kellner [41]; Møller \& Martinsen [42]; Riva et al. [43]; Schievano et al. [44]), indicating that the profitability of biogas production is generally related to factors such as the plant size, the cost of feedstock, initial investment, costs for storage and transportation and biogas yield.

The integration of environmental and economic assessments was only attempted in a few cases. Most of these studies - e.g. Murphy et al. [45], Ayoub et al. [46], Ayoub et al. [47], Luo et al. [48], Santibanez-Aguilar et al. [49], Hennig \& Gawor [50] -, however, focus on the use of dedicated energy crops and their conversion in complex and centralised biorefinery systems used for fuel production. Biogas production from residual materials is investigated, for example, in Yabe [51]. These studies nonetheless are static in nature, as the assessments are carried out at the scenario level. When looking at the co-digestion of residual biomass and energy crops, no studies were found to have attempted to optimise biogas production by dynamically modelling individual sub-parts of the biogas chain.

Therefore, the objective of the study presented herein is to develop a joint value-chain, energy and environmental model, to be used for optimising biogas chain production. This model is meant to provide advice to managers and decision makers in the form of a holistic evaluation of risks and benefits in producing biogas using sugar beet pulp silage (SB). This objective is achieved by 1 ) developing detailed economic, GHG 
emission, energy and mass models for the biogas chain, 2) integrating these models into a single framework capable of describing the relationships between economy, energy and emissions, while taking into consideration scaling effects, 3 ) applying the model to optimise the use of beet roots in manure co-digestion and 4) identifying the optimal scale of the biogas plant.

\section{Materials and Methods}

\subsection{The biogas production chain}

As shown in Figure 1, the biogas production chain assessed herein consists of five main process units, including:

- Raw material input: cultivation and harvesting stages

- Pre-treatment: washing, slicing and ensiling

- Transportation: transportation to the biogas plant and transportation to the farm

- Energy production: mixing tank, anaerobic digester, post-digestion plant and combined-heat-and-power (CHP) plant or gas upgrade for the gas transmission net

- Digestate process and fertiliser unit: after-storage and field stages

Sugar beet is first cultivated and then harvested between September and mid- or late November [52]. While harvesting, the root is separated from the beet top and left on the field. Beet roots carry a significant amount of soil, and so a cleaning step is thus required. Cleaning is normally performed at the farm level, but centralised cleaning can occur in some cases. The soil removed from the root is returned to the field. Sugar beets harvested in November are then stored in clamps covered with straw [52]. In February, the roots are chopped finely into beet pulp and moved into silos for 18 months (i.e. until September next year). Ensiling leads to the degradation of some organic pools, so that total solids (TS) and volatile solids (VS) contents change, while GHG are emitted. When needed, SB is collected and then mixed with pig slurry (PS) to a known ratio, and the mixture is then pumped into an AD reactor. PS is the main substrate, whereas $S B$ is the cosubstrate providing different benefits to the process: it contains abundant trace elements for microbial growth, it has a strong buffer capacity, thereby helping to maintain $\mathrm{pH}$ neutrality, and it is a good diluter for toxic compounds potentially contained in the manure. In the present study, the co-digestion of three massbased ratios of PS and SB in the feedstock is analysed:

- PSSB-0: $100 \%$ PS, $0 \%$ SB

- PSSB-12.5: 87.5\% PS, $12.5 \%$ SB

- PSSB-25: 75\% PS, 25\% SB

The additional use of SB (i.e. a 50/50 ratio) was attempted in preliminary tests; however, the anaerobic digestion operation was unstable with the accumulation of VFAs and a drop in $\mathrm{pH}$ level.

The main product of the digestion process is biogas (i.e. a mix of $\mathrm{CO}_{2}, \mathrm{CH}_{4}$ and other trace gases), which can be used for electricity and/or heat production, or fed to the natural gas grid. Depending on the final recipient and the energy conversion technology employed, biogas may need to be upgraded to remove most of its $\mathrm{CO}_{2}$ and other trace compounds. The by-product of the digestion process is a type of slurry called "digestate," which is typically partly dewatered and further stabilised by means of aerobic composting. The finally cured digestate may be stored further until its final application to agricultural land as a fertiliser and soil amendment agent. The calculations herein considered a field-application scenario where digestate is applied in early spring, prior to seeding a spring cereal crop.

In the biogas production chain, the economy of scale can be a significant factor affecting the profitability of a project. In fact, while production costs per unit of biomass handled may be reduced in large facilities, transportation costs may increase significantly, due to the larger size of the catchment area for the biomass. To assess the scale effect, economic analysis was thus performed on three facilities: small (i.e. using 110,000 $\mathrm{Mg}$ of biomass per year), medium (i.e. $320,000 \mathrm{Mg} / \mathrm{year}$ ) and large (i.e. $500,000 \mathrm{Mg} /$ year). The size of the plant is assumed not to have an effect on mass and energy balances. 


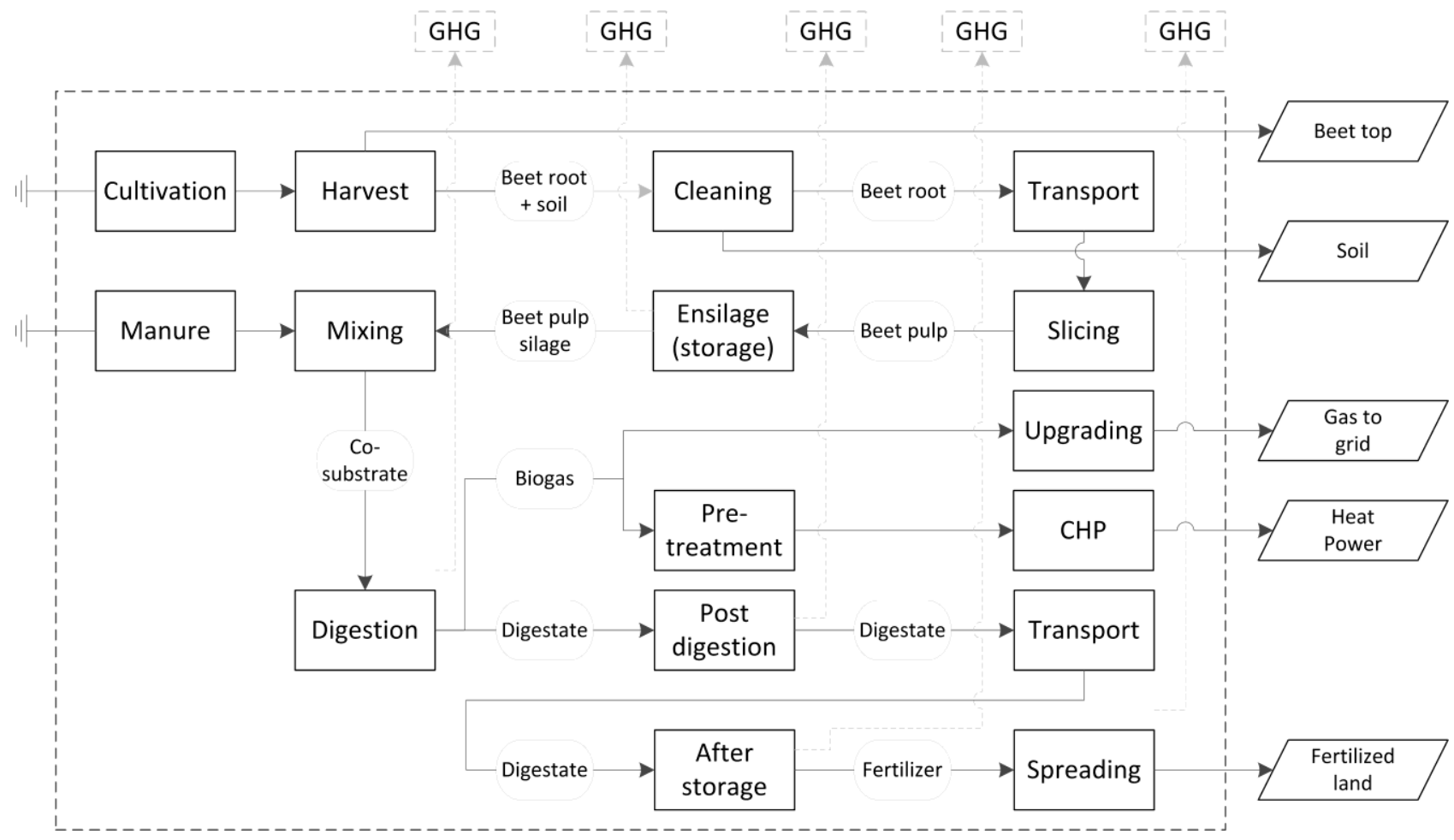

Figure 1 - Overview of the biogas chain model.

\subsection{The mass balance model}

We based mass balance calculations on both the literature and experimental data. Input and outputs from individual processes in the biogas chain were modelled by tracking digestible $\left(V_{\mathrm{D}}\right)$ and non-digestible $\left(\mathrm{VS}_{\mathrm{ND}}\right)$ components of VS. In the model, we defined lignin as $\mathrm{VS}_{\mathrm{ND}}$, as it is non-degradable in an anaerobic environment [13]. The remaining VS (i.e. total VS minus lignin) was defined as VS $S_{D}$. The basis for the mass balance calculation was $1000 \mathrm{~kg}$ of feedstock fed into a biogas digester. The mass balance model included stages shown in Figure 1, as explained in the previous section. We reconciled and displayed mass and energy balances using STAN, a software package used for material and substance flow analysis [53].

For the harvested sugar beet, we used data from Schoups et al. [54] and Thalbitzer [55], to determine mass distribution into roots, tops and soil. Harvested beet root accounted for $70.7 \%$ of the total mass, whereas beet tops were $25.6 \%$ and soil $3.8 \%$. The total solids (TS) in the root were $226 \mathrm{~g} / \mathrm{kg}$, and VS was 208 $\mathrm{g} / \mathrm{kg}$. While the top is removed, the root and attached soil are moved further on to the cleaning step. The amount of soil left after the wet washing step was assumed to be $2.1 \%$ of TS. Since soil contains mostly ash ( $85 \%$ in TS), the VS concentration is slightly lower than the case where the root is without soil.

We assumed the pulping process would involve no mass loss, and we modelled the storage process for the beet root as employing two sub-processes, both responsible for significant VS degradation (i.e. $28 \%$ and $12 \%$ respectively, Table S2 in supporting information) and any subsequent decrease in biogas production during AD. For the sake of simplicity, the two storage sub-processes were represented by one overall storage process in the mass balance model.

We experimentally measured the composition of SB and PS, as well as biogas production data during $A D$ from different sources (details provided in the supporting information). We carried out physicochemical analysis of PS and SB according to the standard procedure (APHA standard method [56], see supporting information), and we determined biochemical methane potential (BMP) according to VDI 4630 (2006). We also investigated the $A D$ of different feedstock mixes using a 20 litre continuous flow stirred-tank reactor (CSTR) in a mesophilic condition $\left(37^{\circ} \mathrm{C}\right)$, with a hydraulic retention time (HRT) of 20 days. Data for the 
individual co-digestion mixing ratios are presented in Table 1, where it is evident that contributions of VS from SB and PS are considerably different for the analysed scenarios. For example, in the PSSB- 25 scenario, $58 \%$ of VS is from SB while $42 \%$ is from PS, while approximately 63 and $37 \%$ of VS originates from SB and PS, respectively, in the PSSB-12.5 ratio. The prime feedstock (i.e. PS) had biochemical methane potentials (BMP) of $296 \mathrm{NL} \mathrm{CH}_{4} / \mathrm{kg}_{\mathrm{vs}}\left(9.42 \mathrm{NL} \mathrm{CH}_{4} / \mathrm{kg}_{\mathrm{ww}}\right)$. The BMP of SB was $424 \mathrm{NL} \mathrm{CH}_{4} \mathrm{~kg} / \mathrm{kg}_{\mathrm{vs}}\left(54.8 \mathrm{NL} \mathrm{CH}_{4} / \mathrm{kg}_{\mathrm{ww}}\right)$. During CSTR experiments, $43.4-55.9 \%$ of VS was transformed into biogas (supporting information, Table S5). When only PS was digested, $\mathrm{CH}_{4}$ production was $9.10 \mathrm{CH}_{4} \mathrm{NL} / \mathrm{kg}_{w w}$, while $\mathrm{CH}_{4}$ productions from the PS and SB mixtures were $12.3 \mathrm{NL} \mathrm{NH}_{4} / \mathrm{kg}_{w w}$ and $18.0 \mathrm{NL} \mathrm{CH}_{4} / \mathrm{kg}_{\mathrm{ww}}$ for PSSB-12.5 and PSSB-25, respectively. Using the equation provided by Sommer et al. [4], methane emissions post-storage were estimated at $0.30-1.99 \mathrm{NL} \mathrm{CH}_{4} / \mathrm{kg}_{\mathrm{ww}}$. Additional details are provided in the supporting information.

Table 1 - Composition of co-feedstock and biochemical methane potentials (BMP) for biogas production at different co-digestion mixing ratio scenarios.

\begin{tabular}{|c|c|c|c|c|c|c|c|c|}
\hline \multirow[b]{2}{*}{ Parameter } & \multirow[b]{2}{*}{ Unit } & \multirow{2}{*}{$\begin{array}{c}\text { PSSB-0 } \\
\text { PS }\end{array}$} & \multicolumn{3}{|c|}{ PSSB-12.5 } & \multicolumn{3}{|c|}{ PSSB-25 } \\
\hline & & & PS & BS & Co-feed & PS & BS & Co-feed \\
\hline Wet mass & g & 1,000 & 875 & 125 & 1,000 & 750 & 250 & 1,000 \\
\hline \multirow[t]{2}{*}{ TS } & $\mathrm{g}$ & 37.7 & 33.0 & 22.4 & 55.4 & 28.3 & 44.9 & 73.2 \\
\hline & $\% w w$ & 3.8 & 3.8 & 17.9 & 5.5 & 3.8 & 17.9 & 7.3 \\
\hline \multirow[t]{2}{*}{ Water } & g & 962 & 842 & 103 & 945 & 722 & 205 & 927 \\
\hline & $\%$ ww & 96.2 & 96.2 & 82.1 & 94.5 & 96.2 & 82.1 & 92.7 \\
\hline \multirow[t]{2}{*}{ VS } & $\mathrm{g}$ & 31.8 & 27.8 & 16.2 & 44.0 & 23.9 & 32.3 & 56.2 \\
\hline & $\%$ TS & 84.4 & 84.4 & 72.0 & 79.4 & 84.4 & 72.0 & 76.8 \\
\hline \multirow[t]{2}{*}{ Ash } & $\mathrm{g}$ & 5.9 & 5.2 & 6.3 & 11.4 & 4.4 & 12.5 & 17.0 \\
\hline & $\%$ TS & 15.6 & 15.6 & 28.0 & 0.0 & 15.6 & 28.0 & 0.0 \\
\hline \multicolumn{9}{|l|}{ VS Pools } \\
\hline \multirow[t]{2}{*}{$\mathrm{VS}_{\mathrm{D}}$} & $\mathrm{g}$ & 28.2 & 24.7 & 13.8 & 38.5 & 21.1 & 27.6 & 48.7 \\
\hline & $\%$ VS & 88.6 & 88.6 & 85.3 & 86.7 & 88.6 & 85.3 & 86.7 \\
\hline \multirow[t]{2}{*}{$\mathrm{VS}_{\mathrm{ND}}$} & g & 3.6 & 3.2 & 2.4 & 5.5 & 2.7 & 4.8 & 7.5 \\
\hline & $\%$ VS & 11.4 & 11.4 & 14.7 & 13.3 & 11.4 & 14.7 & 13.3 \\
\hline \multicolumn{9}{|c|}{ Biogas potential } \\
\hline \multirow[t]{2}{*}{ BMP } & $\mathrm{NLCH} 4 / k g v s$ & 296 & 296 & 424 & 342 & 296 & 424 & 370 \\
\hline & $\mathrm{NLCH} 4 / \mathrm{kg}_{\mathrm{ww}}$ & 9.4 & 9.4 & 54.8 & 15.1 & 9.4 & 54.8 & 20.8 \\
\hline
\end{tabular}

PS: pig slurry; SB: sugar beet pulp silage ; VS : degradable VS; VS $\mathrm{ND}_{\mathrm{ND}}$ non-degradable VS; ww: wet weight; TS: total solids; VS: volatile solids; BMP: biochemical methane potential.

\subsection{The energy balance model}

For individual flows of materials in the system, we assumed an energy content ( $\mathrm{H}_{\mathrm{aw}}$, ash- and water-free) of $20.5 \mathrm{MJ} / \mathrm{kg}_{\mathrm{vs}}$ and $26.6 \mathrm{MJ} / \mathrm{kg}_{\mathrm{Vs}}$ for the $\mathrm{VS} \mathrm{S}_{\mathrm{D}}$ and $\mathrm{VS} \mathrm{S}_{\mathrm{ND}}$ respectively. As specific data for $\mathrm{VS} \mathrm{S}_{\mathrm{D}}$ and $\mathrm{V} \mathrm{S}_{\mathrm{ND}}$ does not exist, we derived these values through data reconciliation, in order to fit the energy balance with respect to the energy content of the inputs, outputs and biogas production. These estimated values are in accordance with data reported for cellulose/hemicellulose and lignin materials. Energy related to the cultivation and harvesting of sugar beet was $0.334 \mathrm{MJ} / \mathrm{kg}$, taken as cumulative energy demand for the Ecoinvent ( $\mathrm{v} 2.2$ ) process 'Sugar beet, from farm'. We assumed the production of PS as being burden-free, meaning that energy and material consumptions utilised for animal growth were excluded from the calculation.

For transportation, we based diesel consumption on estimated driven distances (see later) and assumed a consumption factor of $0.02645 \mathrm{l} / \mathrm{tkm}$ (Ecoinvent process 'Transport, lorry $>32 \mathrm{t}$, EURO5'). For the energy balance, we assumed that diesel has an energy content of $43.1 \mathrm{MJ} / \mathrm{kg}$, a density of $0.832 \mathrm{Mg} / \mathrm{m}^{3}$ and a cumulative primary energy content of $54.8 \mathrm{MJ} / \mathrm{kg}$ (Ecoinvent process 'Diesel, low-sulphur, at regional storage'). We estimated energy consumption during ensilage at $150 \mathrm{MJ} / \mathrm{Mg}$ and $6.7 \mathrm{MJ} / \mathrm{Mg}$, based on Ecoinvent processes 'Baling $/ \mathrm{CH}^{\prime}$ and 'Loading bales $/ \mathrm{CH}^{\prime}$, respectively, and assumed that each bale contained 
$\sim 1.3 \mathrm{Mg}$ of beet root. The spreading of digestate on land requires $0.26 \mathrm{~L} / \mathrm{m}^{3}$ of diesel (Ecoinvent process 'Slurry spreading, by vacuum tanker').

We estimated electricity consumption for operating the biogas plant at $30 \mathrm{MJ} / \mathrm{Mg}$ [22], while the energy requirement for heating up the feedstock was estimated at $121 \mathrm{MJ} / \mathrm{m}^{3}$ of slurry (or $1800 \mathrm{MJ} / \mathrm{Mg}_{\mathrm{Ts}}$ ). For the estimation, we assumed that the average temperature of the inlet material was $T_{\text {in }}=8^{\circ} \mathrm{C}$ and that the slurry had a density and specific heat similar to water (i.e. $1000 \mathrm{~kg} / \mathrm{m}^{3}$ and $4.19 \mathrm{~kJ} / \mathrm{kg} / \mathrm{K}$ ); additional details are provided in the supporting information. The biogas produced is combusted in an engine (i.e. Jenbacher 420), with conversion efficiencies of 40 and $42 \%$ for electricity and heat, respectively [57]. Part of the produced energy is used for operating the plant, while the surplus of electricity and heat is delivered, respectively, to the electricity network and district heating facilities. For electricity, cumulative primary energy was assumed

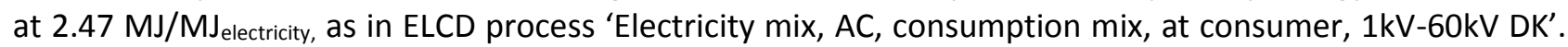
For heat, cumulative primary energy was assumed at $1.55 \mathrm{MJ} / \mathrm{MJ}_{\text {heat, }}$ as reported by the Danish Energy Agency [58].

\subsection{The GHG model}

We established the GHG balance using the conversion factors for diesel combustion, electricity and heat (reported in Table 2) applied to the individual energy inputs described previously. The loss of biogas due to fugitive emissions from the plant is rather uncertain, as very few measurement studies at full-scale plants have been conducted so far. In the present study, we assumed that the fugitive emission of $\mathrm{CH}_{4}$ corresponds to $3.1 \%$ of the $\mathrm{CH}_{4}$ production in the biogas plant, as estimated by Flesch et al. [59] for an agricultural biodigester, including storage of the digestate.

We predicted the short-term emission of $\mathrm{N}_{2} \mathrm{O}$ using the $\mathrm{N}_{2} \mathrm{O}$ sub-model developed by Sommer et al. [4], which considers $\mathrm{N}_{2} \mathrm{O}$ emission to be a function of VS in slurry or digestate, reactive slurry nitrogen (N) and soil water potential $(\psi)$. As explained in the supporting information, the model makes use of the $V S_{D}$ and $V S_{N D}$ introduced in section 2.3. For model calculations of $\mathrm{N}_{2} \mathrm{O}$ emissions, we assumed an application rate of $100 \mathrm{~kg}$ $\mathrm{NH}_{4}{ }^{+}-\mathrm{N} /$ ha. Following Sommer et al. [4], the nitrification of reactive $\mathrm{N}$ in slurry hotspots was assigned an $\mathrm{N}_{2} \mathrm{O}$ emission factor (EF) of $0.5 \%$, and the nitrification of $\mathrm{N}$ from digestate or slurry in the surrounding soil was allocated an EF of $0.2 \%$. We calculated total denitrification in the slurry clumps as a function of $\mathrm{VS}_{\mathrm{D}}$ in the hotspot, and the resulting $\mathrm{N}_{2} \mathrm{O}$ emission was estimated by assuming an EF of $2 \%$. Total $\mathrm{N}_{2} \mathrm{O}$ emissions produced by nitrification in clumps and soil, and by denitrification in clumps, were expressed on an area basis but also relative to slurry/digestate VS. The calculation considered a field-application scenario where slurry/digestate is applied in early spring, prior to seeding a spring cereal crop. We assumed an $\mathrm{NH}_{3}$ loss of $10 \%$ during application, and soil-water potential was set to $-0.015 \mathrm{MPa}$, i.e. close to field capacity.

We estimated $V S_{D}$ in digestate and untreated feedstock from the short-term evolution of $\mathrm{CO}_{2}-\mathrm{C}$ after incubating slurry/digestate in soil under aerobic conditions. We assumed that $\mathrm{VS}_{D}$ in applied materials would be fully degraded when $\mathrm{CO}_{2}$ evolution rates became constant. The six incubation tests included three samples of digested material, two samples of raw feedstock and one control (i.e. only soil); each test included five replicates. The digestate samples were produced in CSTR experiments, as explained in section 2.2. The three samples of digestate corresponded to feedstock mixtures previously described (i.e. PSSB-0, PSSB-12.5, PSSB25), while the two samples of raw feedstock included undigested PS and SB. The main physicochemical properties of the materials used for the incubation tests are reported in the supporting information (Table S3 and S8), together with a description of the experimental setup (Table S7), the gas sampling procedure, the data analysis and the estimation of $\mathrm{N}_{2} \mathrm{O}$ emissions for the analysed scenarios (Table $\mathrm{S} 9$ and Table $\mathrm{S} 10$ ).

We converted the emissions of different gases to $\mathrm{CO}_{2}$-equivalent emissions, by using the following 100year global warming potentials (GWPs): $1 \mathrm{~kg} \mathrm{CO} 2 \mathrm{eq} / \mathrm{kg} \mathrm{CO}$ for fossil $\mathrm{CO}_{2}, 28 \mathrm{~kg} \mathrm{CO} 2 \mathrm{eq} / \mathrm{kg} \mathrm{CH}$ for biogenic $\mathrm{CH}_{4}, 30 \mathrm{~kg} \mathrm{CO}$ eq/ $/ \mathrm{kg} \mathrm{CH}$ for fossil $\mathrm{CH}_{4}, 265 \mathrm{~kg} \mathrm{CO}$ eq $/ \mathrm{kg} \mathrm{N} \mathrm{N}_{2} \mathrm{O}$ for $\mathrm{N}_{2} \mathrm{O}$ (according to IPCC [60]) and $0 \mathrm{~kg}$ $\mathrm{CO}_{2} \mathrm{eq} / \mathrm{kg} \mathrm{CO}$ for biogenic $\mathrm{CO}_{2}[61]$. 
Table 2 - Emissions factors for energy inputs to the biogas chain.

\begin{tabular}{|c|c|c|c|}
\hline Process & Unit & Amount & Note, reference \\
\hline Diesel combustion & kg CO2-eq/liter & 3.1 & $\begin{array}{l}\text { Provision + combustion } \\
\text { (Fruergaard et al., 2009) }\end{array}$ \\
\hline Electricity production & kg CO2-eq /kWh & 0.95 & $\begin{array}{c}\text { Hard coal, NORDEL (Fruergaard } \\
\text { et al., 2009) }\end{array}$ \\
\hline Heat production & kg CO2-eq/GJ & 72 & $\begin{array}{l}\text { District heating, natural gas } \\
\text { (Fruergaard et al., 2009) }\end{array}$ \\
\hline
\end{tabular}

\subsection{The economic model}

In the following, the economic model is described briefly, while additional details are provided in supporting information. The objective of the economic model was to determine the total net income (TNI) of different scenarios, where we define the $T N I\left(p_{k}, M_{j}, M_{k}, r_{j} j_{k}\right)$ as (Equation 1):

$$
\operatorname{TNI}\left(p_{k}, M_{j}, M_{k}, r_{j}, j, k\right)=T I\left(p_{k}, M_{k}\right)-T C\left(M_{j}, M_{k}, j, k\right)
$$

where $\operatorname{TI}\left(p_{k}, M_{k}\right)$ is the total income as a function of the price $p_{k}$ of output $k$ and the mass $M_{k}$ of output $k$; $T C\left(M_{j}, M_{k}\right)$ is the total cost as a function of the mass $M_{j}$ of biomass $j$ and the mass $M_{k}$ of output $k$ and the index $j$ and $k$ are objects of the set $J$ of input biomass (i.e. PS and SB) and the set $K$ of output (i.e. digestate, biogas), respectively.

\subsubsection{Income}

Total income $T I\left(p_{k}, M_{k}\right)$ is the sum of the prices paid for the different outputs and is defined as (Equation 2):

$$
\operatorname{TI}\left(p_{k}, M_{k}\right)=\sum_{k \in K} p_{k} M_{k} \quad \text { (Equation 2) }
$$

where $M_{k}$ is the mass of output $k$ (i.e. digestate, $M_{\text {dig, }}$ biogas, $M_{g a s}$ ) and $p_{k}$ is the price of output $k$.

The factor $M_{k}$ is a function of the process yield, which is in turn a function of different operational parameters, such as feedstock composition and HRT in the process, as explained and estimated in section 2.2. We estimated the prices $p_{k}$ of the digestate $\left(p_{\text {dig }}\right)$ and biogas $\left(p_{\text {gas }}\right)$ based on market considerations. In an agricultural context, digestate has some value because of its fertilising potential and reduced smell in the area. The $p_{\text {dig }}$ depends on the specific supplier agreement between the operator of the biogas plant and farmers, thereby including the requirement of the farmer to dispose of the PS.

We estimated $p_{\text {gas }}$ in Denmark based on the final use of the biogas and the level of public support. We considered the following two options:

- Biogas is upgraded and fed to the natural gas network.

- Biogas is used locally in a combined heat and power (CHP) plant.

When biogas production exceeds a specific amount, hereby estimated as 3.5 million $\mathrm{m}^{3}$ per year, it was calculated that biogas was upgraded and fed into the natural gas grid. In this case (Equation 3 ), the selling price of the biogas ( $p_{\text {gas, } U P}$ ) is determined by the market price for the natural gas $\left(p^{N G}\right)$, the support level $(S)$ and a potential green factor $\left(p^{g}\right)$, corresponding to the market price for "being green", determined from sales of green certificates.

$$
p_{g a s, U P}=p^{N G}+p^{g}+S
$$

\section{(Equation 3)}

When biogas is used at a CHP plant, its price $\left(p_{\text {gas, СHP }}\right)$ is a combination of the price of biogas as such and a market power value, as shown in (Equation 4): 


$$
p_{\text {gas }, C H P}=p\left(p_{N G}, S, p_{H P}\right)-p_{M P}
$$

where $p_{N G}$ is the price of natural gas, $S$ is the level of public support given to the CHP, $p_{H P}$ is the price of heat and power generated and sold to the market and $p_{M P}$ is the market power value, which depends on the structure of the power market (e.g. user and supplier are monopolist, or alternative supply/production options exist).

\subsubsection{Costs}

From the biogas plant perspective, total cost $T C\left(M_{j}, M_{k}\right)$ is expressed as (Equation 5):

$$
T C\left(M_{j}, M_{k}\right)=C_{\text {trans }}\left(M_{j}, M_{k}, G P_{k}\right)+C_{\text {opex }}\left(M_{j}, M_{\text {gas }, U P}\right)+C_{\text {capex }}\left(M_{j}, M_{k}\right)
$$

where $C_{\text {trans }}\left(M_{j}, M_{k}, G P_{k}\right)$ is the transport cost, $C_{\text {opex }}\left(M_{j}, M_{\text {gas, }}, \mathrm{P}\right)$ is the operational cost and $C_{\text {capex }}\left(M_{j}, M_{k}\right)$ is the cost of investments. The $C_{\text {trans }}$ is a combination of the costs borne for transporting PS and SB to the AD plant, as well as the costs for transporting digestate and biogas away from the plant, as shown in Equation 6 .

$$
C_{\text {trans }}\left(M_{j}, M_{k}, G P_{k}\right)=C_{\text {trans }, \text { in }}\left(M_{j}\right)+C_{\text {trans,out }}\left(M_{\text {man }}, M_{k}, G P_{k}\right)
$$

where $C_{\text {trans,in }}$ represents the cost of transporting the PS/SB to the AD plant and $C_{\text {trans, out }}$ is the cost related to the transportation of digestate and biogas away from the $A D$ plant.

The size of the plant will hence influence transportation costs significantly, as a larger plant will involve longer driving distances, to ensure the supply of the required biomass. To estimate transportation distances according to the size of the plant, the supply area was modelled using concentric circles around the biogas plant, whereby availability and supply cost of PS/SB could be estimated as a function of the radius (i.e. the distance from the plant). With respect to digestate transportation, it was considered that a share of the digestate could be transported back to the some farmers delivering PS. The maximum amount that could be returned to individual farmers was set to $115 \%$ of the PS they delivered; any excess sludge would involve additional costs for its transportation to other farmers. A detailed description of the calculation is provided in the supporting information.

Operational expenditures $C_{\text {opex }}$ for the biogas plant are estimated as follows (Equation 7):

$$
C_{\text {opex }}\left(M_{j}, M_{\text {gas }, U P}\right)=C_{\text {opex,input }}\left(M_{j}\right)+C_{\text {opex }, \text { oper }}\left(M_{j}, M_{\text {gas }, U P}\right) \quad \text { (Equation 7) }
$$

where $C_{\text {opex,input }}$ represents the cost of buying PS/SB beet according to the market prices and $C_{\text {opex,oper }}$ is cost related to operating the biogas plant, including the following factors (Equation 8):

$C_{\text {opex }, \text { oper }}\left(M_{j}, M_{\text {gas }, U P}\right)=C_{\text {basis }}\left(\sum_{j \in J} M_{j}\right)+\left(C_{\text {wear }}+C_{\text {pow }}+C_{\text {man }}\right) \cdot M_{\text {sug }}+C_{\text {opex }, U P}\left(p_{\text {pow }}, M_{\text {gas }, U P}\right)$

(Equation 8)

where $C_{\text {basis }}$ is the basis cost of a biogas plant with size $\sum_{j \in J} M_{j}, C_{\text {wear }}$ is the cost of wear per $\mathrm{Mg}$ of SB, $C_{\text {pow }}$ is the cost of power per $\mathrm{Mg}$ of $\mathrm{SB}, C_{\text {man }}$ is the cost of manpower per $\mathrm{Mg}$ of extra $\mathrm{SB}$ and $M_{\text {sug }}$ is the total mass of SB. $C_{o p e x, U P}$ is the cost for biogas upgrading, which is a function of the amount of biogas upgraded $\left(M_{\text {gas }}, \mathrm{UP}\right)$ and the price of power $\left(p_{\text {pow }}\right)$.

Investment costs $\left(C_{\text {capex }}\right)$ depend on investments related cost-wise to input, production and output. As in this model it is assumed that all transportation is rented (i.e. no investment costs for trucks and other), and the $C_{\text {capex }}$ is defined as (Equation 9): 
$C_{\text {capex }}\left(M_{j}, M_{k}\right)=C_{\text {capex,prod }}\left(M_{j}\right)+C_{\text {capex,output }}\left(M_{j}, M_{k}\right)$

(Equation 9)

where $C_{\text {capex,prod }}$ is the investment cost for production, including the biogas plant, the process heat boiler, the purchase of land, counselling and other elements, and $C_{\text {capex, output }}$ is the investment cost for output, including the storage of digestate, the storage of biogas and the biogas cleaning/upgrading facility. The depreciation time for the biogas facility is assumed being 20 years, as recommended by Ea Energianalise to the Danish Energy Agency [62].

\section{Results and Discussion}

\subsection{Mass and energy balance}

We reconciled mass balances for the PSSB-0, PSSB-12.5 and PSSB- 25 feedstock mixtures, including wet weight, TS and VS. An example of mass balance for PSSB-12.5 is presented in Figure 2 and Figure 3, while remaining figures are provided in the supporting information (section 4).

We found that, when looking at the wet mass, PS represents the most significant flow in all of the scenarios analysed. However, when SB is added to the feedstock in scenarios PSSB-12.5 and PSSB-25, this flow represents the major input of VS and TS into the system. We found similar results in the energy balance (Figure 4), indicating that, as expected, even a relatively small addition of SB significantly increases the throughput of energy in the system while significantly boosting biogas yield (both total production and yield per Mg of input). PS indeed represents a preferable mean for diluting the high content of solids in SB instead of freshwater: besides the significant savings of water resources (and connected expenses), the use of PS as a prime co-substrate provides better nutrient balancing and increased buffering capacity.

Digestate represents the main output of the system, regardless of the feedstock mixture considered, the reason being the substantial amount of water carried as a result. With regards to VS, the situation is rather different, as the majority of VS is converted into gaseous compounds during the AD process. While biogas is used for energy production, the significant amount of gas forming during ensiling represents a loss of energy within the system; this loss, however, is almost unavoidable, as sugar beet storage is needed to ensure the supply of feedstock to the reactor throughout the whole year. The addition of SB to the feedstock mixture has a clear effect on biogas production (per unit of input), which almost doubles - going from PSSB-0 to PSSB25 (Table 3). This result is a combination of three aspects: an increase in the BMP of the input (Table 3), an increase in VS content in the feedstock (from 3.2\% ww in PSSB-0 to 5.6\% ww in PSSB-25) and a decrease in the ratio between biogas yield and the BMP (Table 3). The latter suggests that, when adding SB, some adjustments in the digestion process HRT may be needed, to exploit further the methane potential of the feedstock material.

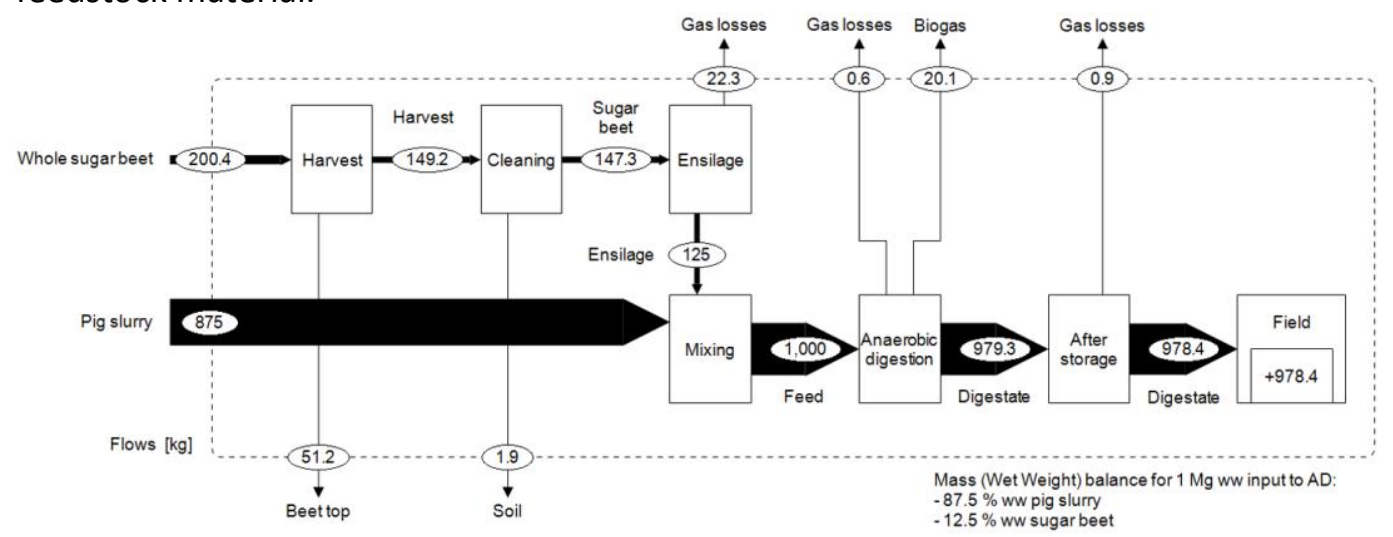

Figure 2 - Mass ( $\mathrm{kg}$, wet weight) balance of the biogas chain relative to $1 \mathrm{Mg}$ ww of input to the anaerobic digester. The input is PSSB-12.5, i.e. a mix of PS (87.5\% ww) and SB (12.5\% ww). 


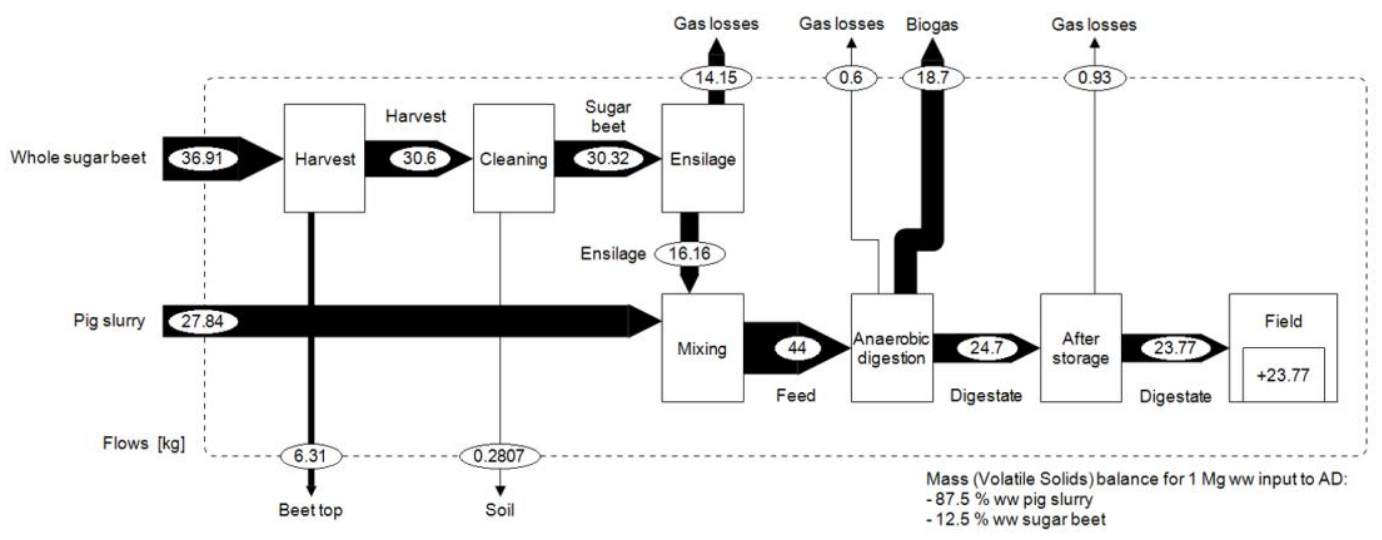

Figure 3 - VS $(\mathrm{kg})$ balances of the biogas chain relative to $1 \mathrm{Mg}$ ww of input to the anaerobic digester. The input is PSSB-12.5, i.e. a mix of PS (87.5\% ww) and SB (12.5\% ww).

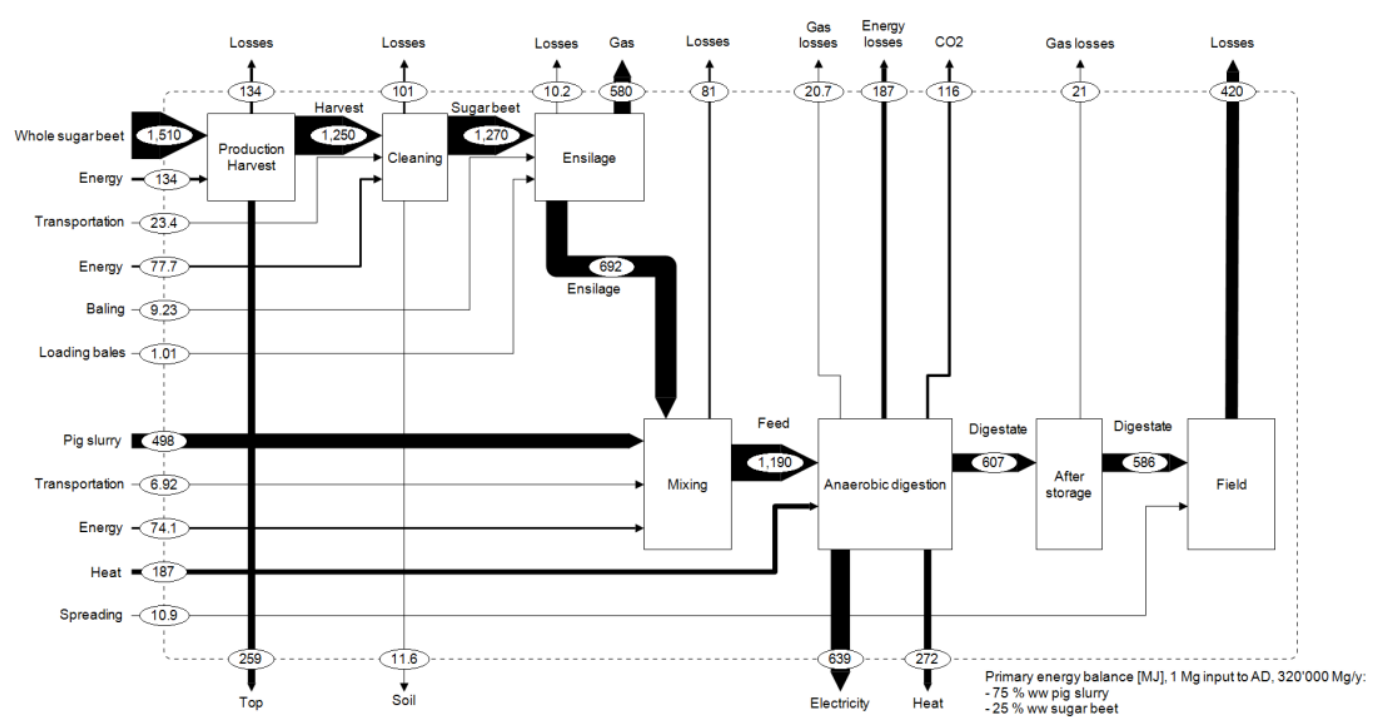

Figure 4 - Energy balance (MJ of primary energy) of the biogas chain relative to $1 \mathrm{Mg}$ ww of input to the anaerobic digester. The input is PSSB-25, i.e. a mix of PS (75\% ww) and SB ( $25 \% \mathrm{ww})$, while the size of the plant is $320,000 \mathrm{Mg} / \mathrm{y}$.

VS degradation throughout the whole biogas chain is in the order of $45 \%$ to $68 \%$ (Table 3 ) of VS input into the system, whereas VS degradation within the digestion process is in the order of 43 to $56 \%$. This figure is in line with what was reported by Møller et al. [18] for cattle manure (i.e. 21-44\%) and pig manure (i.e. 4778\%), while it is lower than findings for other substrates (e.g. 53-80 in Marañón et al. [63], Gebrezgabher et al. [37], Schievano et al. [64], Delzeit \& Kellner [41]). The results in Table 3 show that, with a fixed HRT, the addition of $\mathrm{SB}$ as a co-substrate decreases $\mathrm{CH}_{4}$ yield (as percent of the BMP), while the overall VS degradation increases slightly. This is due to the fact that SB contains a larger amount of slowly degradable VS, which in turn possibly requires longer HRT to reach high yields. In general, a significant share of the VS in the digestate is non-degradable in anaerobic conditions (i.e. $21 \%$ for PSSB-0, $17 \%$ for PSSB-12.5, 28\% for PSSB-25). 
Table 3 - Overview of key parameters for the modelling of biogas production.

\begin{tabular}{llccc}
\hline Parameter & Unit & PSSB-0 & PSSB-12.5 & PSSB-25 \\
\hline $\mathbf{C H}_{4}$ yield & $\mathrm{m}^{3} / \mathrm{Mg}_{\text {ww }}$ input & 9.10 & 12.3 & 18.0 \\
$\mathrm{CH}_{4}$ yield & $\mathrm{m}^{3} / \mathrm{Mgvs}_{\text {input }}$ & 296 & 343 & 369 \\
$\mathbf{C H}_{4}$ yield & \% of BMP & 96.6 & 82.2 & 87.6 \\
$\mathrm{CH}_{4}$ concentration & \% in biogas & 57.2 & 57.1 & 57.2 \\
VS degradation - system & \% VS input to the system & 44.8 & 66.4 & 67.6 \\
VS degradation - digestor & \% VS input to the digestor & 43.5 & 55.6 & 51.2 \\
VS & \% of total VS & 20.6 & 29.4 & 27.8 \\
\hline
\end{tabular}

\subsection{GHG balance}

Our findings show that increasing the share of SB in the feedstock mix results in a significant decrease in $\mathrm{N}_{2} \mathrm{O}$ emissions from land application (Table 4). This is due to the fact that adding SB to the mix enhances both the $\mathrm{C}$ content and the $\mathrm{C}: \mathrm{N}$ ratio of the digestate, thereby increasing $\mathrm{CO}_{2}$ production and decreasing the formation of $\mathrm{N}_{2} \mathrm{O}$ per unit of VS added (see supporting information, section 2.2).

An overview of GHG emissions from the analysed system is presented in Table 5, according to individual sub-processes in the biogas chain. We found that fugitive emissions of gases from the digestion process, and the storage and application on land of digestate, represent a significant contribution to the overall GHG balance (i.e. between 33 and $44 \%$ of direct emissions). Because of a lack of data, some of these estimations may, however, be associated with significant uncertainty. For example, in the present study we assumed fugitive emissions from digestion in the order of $3.1 \%$ of the produced biogas; however, other studies indicate that such a value may be subject to significant variability. For example, fugitive emissions in the order of 0.3$2.6 \%$ were estimated by Liebetrau et al. [65] for 10 agricultural biogas plants in Germany, and 2.1-4.4\% were estimated by Yoshida et al. [66] for a biogas plant treating wastewater treatment plant sludge in Denmark. However, it is generally not well-clarified whether the age/technology of the biogas plant, as well as the feedstock material, has an influence on these emissions. The operation of the digester (i.e. pumping, heating, etc.) also makes some significant contribution to the overall GHG balance, in the order of $16 \mathrm{~kg} \mathrm{CO}$ eq/Mg of feedstock. The use of SB as a co-substrate also significantly influences overall GHG emissions, in that it makes a significant contribution to direct emissions, albeit this is completely counterbalanced by increased biogas production. Energy production (i.e. electricity and heat) from biogas is the most important element in the GHG balance, as it may offset energy production somewhere else in the system (i.e. the results in Table 5 are displayed as negative contributions). In this context, the choice of the alternative source of energy production (herein coal, see table $\mathbf{S 6}$ in supporting information) may have a significant influence on the results.

The results in Table 5 show that, regardless of the size of the plant and the subsequent distance driven, transportation does not make significant contribution to direct GHG emissions. This represents a substantial inconsistency compared with results regarding bioenergy production based solely on energy crops, where transportation did matter, as driven distances were much longer (e.g. Boldrin \& Astrup), while highlighting the importance of both using biomass residues and carefully selecting the location of the biogas plant to ensure the availability of locally (short distance) produced biomasses.

Table 4 - Emissions of $\mathrm{N}_{2} \mathrm{O}$ from applying different digestates on land $\left(\mathrm{NH}_{3}\right.$ loss $10 \%$, soil water potential -0.015 $\mathrm{MPa})$.

\begin{tabular}{lccc}
\hline Treatment & $\begin{array}{c}\mathrm{N}_{2} \mathrm{O} \\
{\left[\mathrm{g} \mathrm{N}_{2} \mathrm{O} / \mathbf{k g}_{\text {vs,applied] }}\right.}\end{array}$ & $\begin{array}{c}\mathrm{N}_{2} \mathrm{O} \text { from } \mathrm{NH}_{3} \text { loss } \\
{\left[\mathrm{g} \mathrm{N}_{2} \mathrm{O} / \mathbf{k g v s}_{\text {applied] }}\right.}\end{array}$ & $\begin{array}{c}\text { Total } \mathrm{N}_{2} \mathrm{O} \\
{\left[\mathrm{g} \mathrm{N}_{2} \mathrm{O} / \mathbf{k g}_{\text {vs,applied] }}\right.}\end{array}$ \\
\hline PSSB-0 & 0.66 & 0.17 & 0.83 \\
PSSB-12.5 & 0.59 & 0.12 & 0.71 \\
PSSB-25 & 0.45 & 0.06 & 0.50 \\
\hline
\end{tabular}


Table 5 - Overview of $\mathrm{GHG}$ emissions [ $\mathrm{kg} \mathrm{CO}_{2} \mathrm{eq} / \mathrm{Mg}$ input] throughout the biogas production chain.

\begin{tabular}{llccc}
\hline & & \multicolumn{3}{c}{ GHG emissions } \\
[kg CO 2 eq/Mg input] \\
Stage & Process & PSSB-0 & PSSB-12.5 & PSSB-25 \\
\hline SB production & SB production & & 11.3 & 22.5 \\
\hline SB transportation & $110,000 \mathrm{Mg} / \mathrm{y}$ & & 0.68 & 1.37 \\
& $320,000 \mathrm{Mg} / \mathrm{y}$ & & 1.04 & 2.08 \\
& $500,000 \mathrm{Mg} / \mathrm{y}$ & & 1.12 & 2.25 \\
\hline PS transportation & $110,000 \mathrm{Mg} / \mathrm{y}$ & 0.59 & 0.52 & 0.44 \\
& 320,000 Mg/y & 0.82 & 0.72 & 0.61 \\
& 500,000 Mg/y & 1.01 & 0.89 & 0.76 \\
\hline SB pre-treatment and storage & Washing & & 4.15 & 8.31 \\
& Baling & & 0.71 & 1.42 \\
& Loading bales & & 0.05 & 0.09 \\
\hline Anaerobic digestion & Milling + pumping & 7.9 & 7.9 & 7.9 \\
& Heat to digester & 8.7 & 8.7 & 8.7 \\
& Electricity production & -34.4 & -46.7 & -68.3 \\
& Heat production & -9.9 & -13.4 & -19.6 \\
& Biogas fugitive losses & 5.6 & 7.6 & 11.2 \\
\hline Digestate storage & Gas losses & 5.9 & 8.0 & 11.4 \\
\hline Application on land of digestate & Spreading & 1.2 & 1.2 & 1.1 \\
& N 2 in field & 4.0 & 3.7 & 4.0 \\
\hline
\end{tabular}

\subsection{Economic analysis}

We estimated total income (TI) for the biogas plant in the range 17.3-24.9 $€ / \mathrm{Mg}$ of input into the biogas plant (Supporting Information, Table S33). Gas subsidies have a significant influence on income (Figure 5 and Figure S8), while market revenue for energy products is less pronounced. Without subsidies, the TNI of biogas production would be negative, thus confirming previous findings (e.g. Gebrezgabher et al. [37], Delzeit \& Kellner [41], Mafakheri \& Nasiri [34]). This highlights the importance of future support policies for the sustainability of biogas production in Denmark. Our findings show positive signs of economies of scale, whereas the composition of the feedstock has an even greater effect on the results, as increasing the utilisation of SB significantly enhances biogas production, albeit not enough to outweigh increased costs related to the SB.

We estimated total costs (TCS) for the biogas production chain in the range 15.8-26.5 $€ / \mathrm{Mg}$ of input into the biogas plant (supporting information, Table S35). Costs, to a high degree, are connected to the feedstock supply, as the price of manure is closely linked to an agreement with farmers, whereby manure is returned in a treated form as digestate; feedstock costs are considered here only as SB costs and account for 0-39\% of the costs, depending on the share of SB utilised (see Figure S9 for details). This figure is in the lower range compared with previous findings by Schievano et al. [44] for maize (i.e. 40-62\%), rye (i.e. 54-67\%), triticale (i.e. $34-48 \%$ ) and sorghum (i.e. 49-62\%) cultivated in a Mediterranean climate. Particularly in the PSSB-0 cases, the positive scale effect on capital costs $\left(C_{\text {capex }}\right)$ becomes clear, while operational costs $\left(C_{\text {opex }}\right)$ dampen the economy of scale effect. The TC is significantly influenced by both the feedstock mix and the scale of the plant. In fact, the SB is so costly that it becomes the most important cost factor in the PSSB-25 cases. Moreover, the utilisation of SB also has an influence on the costs of transportation (which can add up to $20 \%$ of TC), as longer distances need to be covered to guarantee the supply of SB for biogas production. The scale of the plant also influences transportation and $C_{\text {capex }}$ costs, as an increase in plant size requires a larger supply of feedstock with a subsequent increase in driven distance, which varies in the range 5.5-10.3 km for PS and 
0-70.4 km for SB (supporting information, Table S15), depending on the plant size. These figures, however, depend strongly on local farming types (e.g. animal, plant), thereby suggesting that decision making should be based on regional considerations. We estimated costs for transportation in the range 1.1-4.1 $€ / \mathrm{Mg}$, with lower figures associated with small-scale plants not making use of SB. These values are in line with what is reported by, for example, Walla \& Schneeberger [35]. Capital costs $\left(C_{\text {capex }}\right)$ are estimated in the range of 3.1$5.2 € / \mathrm{Mg}$ (supporting information, Table S36), with lower figures referring to large-scale plants. We estimated operation costs $\left(C_{\text {opex }}\right)$ in the range 3.3-4.3 $€ / \mathrm{Mg}$ (Table $\mathrm{S36}$ ). The size of the plant has rather a small influence on the $\mathrm{C}_{\text {opex, }}$ while $\mathrm{C}_{\text {opex }}$ does increase when introducing SB to the feedstock, as additional manpower is needed for handling SB (additional details in supporting information).

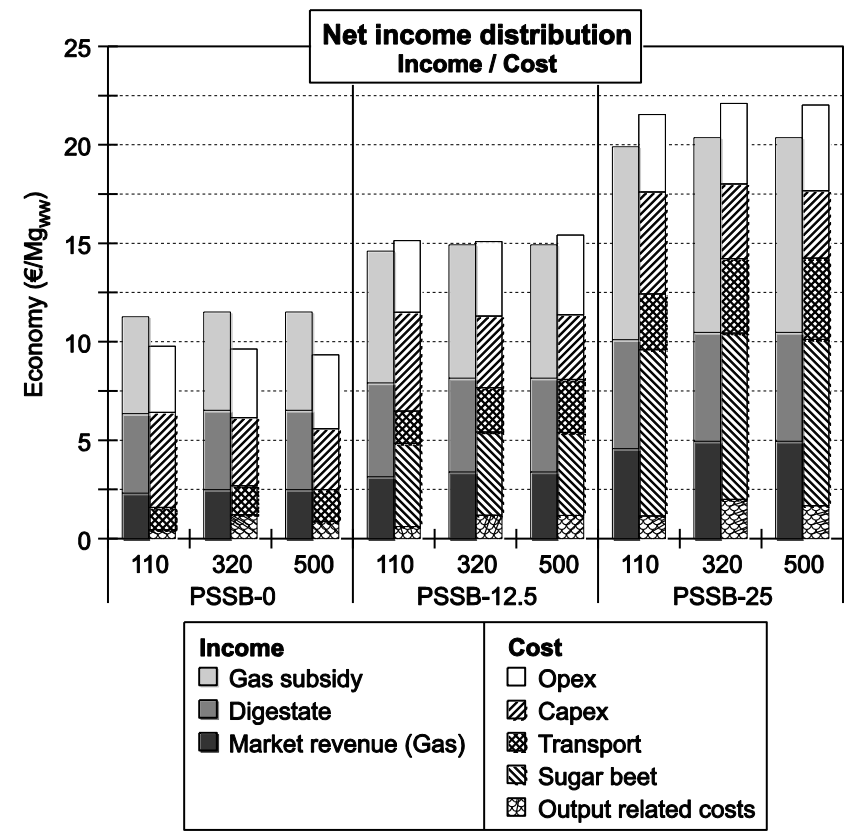

Figure 5 - Distribution of total income (TI) and total costs (TC) per Mg of input to the biogas plant.

An overview of total net income (TNI) is shown in Table 6. Based on existing subsidies, price assumptions for inputs and outputs and the production technology (biogas yield), the only viable input composition is a feedstock containing $0 \%$ of SB (i.e. PSSB-0). In this case the largest plant is the most profitable. Scenarios including SB utilisation as a feedstock (i.e. PSSB-12.5 and PSSB-25) result in negative TNI, as costs are greater than income, due to the fact that increasing costs related to SB input are not counterbalanced by increased biogas production and any associated revenue. Conversely, for the entirely PS-based case (i.e. PSSB-0), the result is positive, meaning that incomes exceed costs. The size of the plant does influence the TNI to some extent, in particular because of the costs associated with transportation (i.e. the larger the plant, the greater the distance) and investment (i.e. the larger the plant, the smaller the investment per unit input). The results presented in Table 6 differ from what was estimated by Delzeit and Kellner [41], as our figures indicate that large-scale facilities have a fundamental potential for better profitability compared with small-scale facilities. For those cases with SB, the benefits of increasing scale are not clear, as we find that the TNI per unit of input is almost neutral in relation to scale. 
Table 6 - Overview of total net income (TNI) $[€ / \mathrm{Mg}]$ for the biogas chain, according to plant size and input mixture.

\begin{tabular}{lcccc}
\hline & & \multicolumn{4}{c}{ Plant capacity (1,000 Mg) } \\
Treatment & Unit & $\mathbf{1 1 0}$ & $\mathbf{3 2 0}$ & $\mathbf{5 0 0}$ \\
\hline PSSB-0 & $€ / \mathrm{Mg}$ & 1.52 & 1.88 & 2.18 \\
PSSB-12.5 & $€ / \mathrm{Mg}$ & -0.54 & -0.17 & -0.50 \\
PSSB-25 & $€ / \mathrm{Mg}$ & -1.64 & -1.74 & -1.66 \\
\hline
\end{tabular}

\subsection{Comparison}

Results for energy balance, GHG emissions and TNI are presented comparatively in Figure 6 , in which it is evident that utilising SB is a major factor influencing the results of the energy, GHG and economic analyses. However, a univocal conclusion cannot be drawn, because while the energy and GHG analyses may suggest that the utilisation of SB as a feedstock into the biogas plant may prove beneficial, the economic analysis indicates that this may be too costly in the long run. As previously described, the only viable input composition is a feedstock containing $0 \%$ of SB (i.e. PSSB-0), whereas increasing utilization of SB results in negative TNI.

The scale of the plant has little influence on the energy and GHG balances, as also indicated in previous studies (e.g. Stephenson et al. [68]); the scale, however, significantly affects net income, while if the biogas plant is operated using solely PS as a substrate, a large-scale plant may be preferable. If an SB co-substrate is employed, it becomes less clear what is preferable. A similar conclusion was reached by Walla \& Schneeberger's [35] study of biogas production in Austria using maize silage as feedstock.

With respect to the results in Figure 6 , we found that the most critical assumptions and main uncertainties are related to the price of SB (relative to manure) and biogas yield in the AD plant. The price of SB is about 4.5 times higher than the PS one. In general terms, production costs for energy crops must be reduced to make biogas production profitable $[35,37,44]$. The increased biogas yield obtained when using SB as a substrate results in better energy and GHG balances, but it does not compensate for increased costs, due to the larger input costs of SB. Biogas yield is indeed a very critical factor for profitability. To reverse negative results for the TNI in Figure 6, a further increase in gas yield (i.e. 5\% for PSSB-12.5 and 13\% for PSSB-25) is needed, thus suggesting that further optimisation of the process is required. The profitability of large-scale facilities seems more affected by biogas yield, as increased biogas generation would allow counterbalancing the costs for longer transportation journeys. In general, improving biogas yield may play an important role in relation to the profitability of biogas production $[34,41,67]$.

Our results (Figure 6) seem to indicate that the low-to-no use of additional co-substrate is preferable for the profitability of biogas production. However, while TNI on a unitary basis (per $\mathrm{Mg}$ input of $\mathrm{m}^{3}$ biogas produced) is better, the overall production of biogas is significantly lower, meaning that achieving renewable energy targets would be more difficult. The TNI results are quite sensitive to biogas yield, SB price and transport distances, and thus small deviations could make adding SB a more profitable undertaking. With respect to the economy of scale, medium- to large-scale plants are probably most favourable. This would, however, require significant planning, where many factors (e.g. type and density of farms) would be taken into account and contextualised to local/regional conditions. Planning should make use of dynamic models to be used for optimisation purposes, taking into consideration a number of uncertainties, which could be a key aspect in decision making. Alternative scenarios to be investigated could include a price/value comparison between upgraded biogas to natural gas quality compared to the actual value of biogas used in local CHPs. In fact, biogas injected into the natural gas grid can be used for more diverse purposes and at more valuable times, thanks to storage advantages. In such a scenario, larger biogas plants may have an advantage in connection with the relatively high investment costs involved in upgrading facilities. 


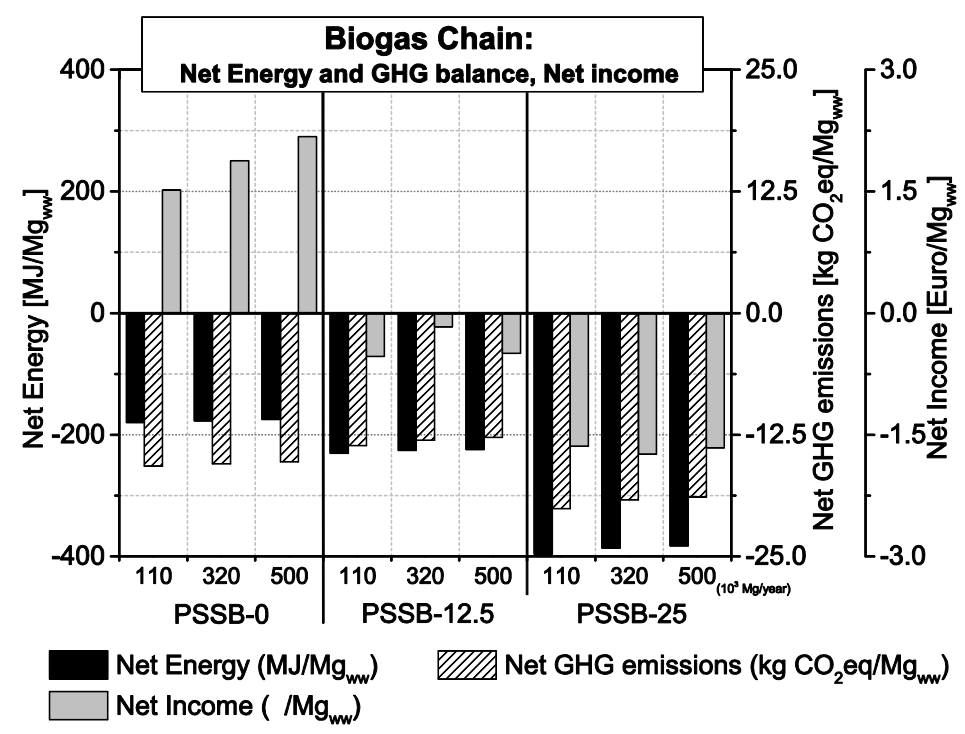

Figure 6 - Comparative overview of net energy balance ( $\mathrm{MJ} / \mathrm{Mg}$ ), net GHG balance (kg CO2eq/ Mg), and $\mathrm{Net}$ Income $(€ / \mathrm{Mg})$ per $\mathrm{Mg}$ ww of input to the biogas plant.

\section{Conclusions}

We carried out an integrated assessment of the biogas production chain based on the co-digestion of pig slurry (PS) and sugar beet pulp silage (SB). The assessment was based on detailed mass, energy and GHG balances, coupled with an evaluation of economic profitability. The influence of feedstock composition was studied using three different feedstocks (i.e. with $0 \% \mathrm{SB}, 12.5 \%$, and $25 \%$ ). The assessment included three sizes (i.e. $110,000 \mathrm{Mg}$ of biomass per year, $320,000 \mathrm{Mg} /$ year and 500,000 Mg/year) of biogas plant to investigate economies of scale. The study was based ostensibly on experimental data and/or data collected specifically and referring to the Danish context.

We found that increasing the share of SB in the feedstock mix has a beneficial impact on energy and GHG balances. This improvement in energy balances is due mostly to increased biogas and energy production, whereas the transportation of feedstock plays a minor role (regardless of the size of the plant). Utilisation of SB was beneficial for the GHG balance, mainly because of reduced $\mathrm{N}_{2} \mathrm{O}$ emissions after applying digestate to land. The results showed that fugitive emissions of $\mathrm{CH}_{4}$ from the biogas plant may make a significant contribution to overall GHG emissions. The profitability of biogas, on the contrary, was negatively affected by the introduction of SB as a co-substrate, as the increase in income from selling biogas was less than the increase in costs associated with buying SB and the transporting it. The subsidy level was established as a key aspect in biogas profitability.

The size of the biogas plant does not significantly influence the energy and GHG balances, as the performance of the conversion process has little to do with scale. Conversely, though, size is important with regards to economic analysis, as an increase in size is associated with reduced capital costs, which are outweighed by SB-related costs in the PSSB-12.5 and PSSB-25 cases, in particular because of the transportation distances involved.

The results indicate overall that utilising energy crops as a co-substrate, while preferable from an energy and GHG balance point of view, is not profitable from an economic point of view. In this respect, we identified the price of $\mathrm{SB}$ and biogas yield as the most sensitive parameters for the results. 


\section{Acknowledgments}

The authors wish to acknowledge the support given by the Danish Council for Strategic Research (DSF), under the "Strategic Research in Sustainable Energy and Environment" research programme, to the project "Optimisation of value chains for biogas production in Denmark (BioChain)". The authors are responsible for the content of this publication.

\section{References}

[1] Triolo JM, Ward AJ, Pedersen L, Sommer SG. Characteristics of animal slurry as a key biomass for biogas production in Denmark. Biomass Now - Sustain Growth Use 2013:30726.

[2] Cordell D, Drangert J-O, White S. The story of phosphorus: Global food security and food for thought. Glob Environ Chang 2009;19:292-305. doi:10.1016/j.gloenvcha.2008.10.009.

[3] Dawson CJ, Hilton J. Fertiliser availability in a resource-limited world: Production and recycling of nitrogen and phosphorus. Food Policy 2011;36:S14-22.

doi:10.1016/j.foodpol.2010.11.012.

[4] Sommer SG, Petersen SO, Møller HB. Algorithms for calculating methane and nitrous oxide emissions from manure management. Nutr Cycl Agroecosystems 2004;69:143-54. doi:10.1023/B:FRES.0000029678.25083.fa.

[5] Dhingra R, Christensen ER, Liu Y, Zhong B, Wu C-F, Yost MG, et al. Greenhouse gas emission reductions from domestic anaerobic digesters linked with sustainable sanitation in rural China. Environ Sci Technol 2011;45:2345-52. doi:10.1021/es103142y.

[6] Energinet.dk. ENERGI 2050 - Udviklingsspor for energisystemet. Energinet.dk, Fredericia, Denmark, 2010. Last accessed June 2015 at <http://www.energinet.dk/SiteCollectionDocuments/Danske\%20dokumenter/El/Fremtiden s\%20energisystem\%20\%20Energi\%202050\%20udviklingsspor\%20for\%20energisystemet\%20rapport.pdf>

[7] Danish Government. Our Future Energy. Danish Government, Copenhagen, Denmark, 2011. Last accessed June 2015 at <http://www.ens.dk/sites/ens.dk/files/policy/danish-climateenergy-policy/our_future_energy.pdf>

[8] NaturErhvervstyrelsen. Vejledning om gødsknings- og harmoniregler. Planperioden 1. august 2013 til 31. juli 2014 (in Danish). NaturErhvervstyrelsen, Danish Ministry of Food, Agriculture and Fisheries, Copenhagen, Denmark, 2013. Last accessed June 2015 at <http://naturerhverv.dk/fileadmin/user_upload/NaturErhverv/Filer/Landbrug/Goedningsre gnskab/Vejledning_om_goedsknings-_og_harmoniregler_20132014_september_2013_6_udgave_1_.pdf> 
[9] Danish Government. Danmark uden affald. Genanvend mere - forbrænd mindre (in Danish). Danish Government, Copenhagen, Denmark, 2013. Last accessed june 2015 at <http://mim.dk/media/mim/67847/Ressourcestrategi_DK_web.pdf>

[10] Tonini D, Astrup T. LCA of biomass-based energy systems: A case study for Denmark. Appl Energy 2012;99:234-46. doi:10.1016/j.apenergy.2012.03.006.

[11] Gylling M, Jørgensen U, Bentsen NS. + 10 mio. tons planen - muligheder for en $\emptyset$ get dansk produktion af bæredygtig biomasse til bioraffinaderier. Fødevareøkonomisk Institut Det Natur- og Biovidenskabelige fakultet Københavns Universitet, Frederiksberg, 2012. Last accessed June 2015 at <http://dca.au.dk/fileadmin/DJF/Bioraf/ti-mio-plan.pdf>

[12] Sommer SG, Husted S. The chemical buffer system in raw and digested animal slurry. J Agric Sci 1995;124:45-53.

[13] Triolo JM, Sommer SG, Møller HB, Weisbjerg MR, Jiang XY. A new algorithm to characterize biodegradability of biomass during anaerobic digestion: influence of lignin concentration on methane production potential. Bioresour Technol 2011;102:9395-402. doi:10.1016/j.biortech.2011.07.026.

[14] Triolo JM, Pedersen L, Qu H, Sommer SG. Biochemical methane potential and anaerobic biodegradability of non-herbaceous and herbaceous phytomass in biogas production. Bioresour Technol 2012;125:226-32. doi:10.1016/j.biortech.2012.08.079.

[15] Hamelin L, Wesnæs M, Wenzel H. Life Cycle Assessment of Biogas from Separated slurry. Environmental Project Nr. 1329, Danish Environmental Protection Agency, Copenhagen, Denmark, 2010. Last accessed June 2015 at <http://www2.mst.dk/udgiv/publications/2010/978-87-92668-03-5/pdf/978-87-92668-042.pdf>

[16] De Vries JW, Groenestein CM, De Boer IJM. Environmental consequences of processing manure to produce mineral fertilizer and bio-energy. J Environ Manage 2012;102:173-83. doi:10.1016/j.jenvman.2012.02.032.

[17] Lansche J, Müller J. Life cycle assessment of energy generation of biogas fed combined heat and power plants: Environmental impact of different agricultural substrates. Eng Life Sci 2012;12:313-20. doi:10.1002/elsc.201100061.

[18] Møller J, Boldrin A, Christensen TH. Anaerobic digestion and digestate use: accounting of greenhouse gases and global warming contribution. Waste Manag Res 2009;27:813-24. doi:10.1177/0734242X09344876.

[19] Bernstad A, la Cour Jansen J, Aspegren H. Life cycle assessment of a household solid waste source separation programme: a Swedish case study. Waste Manag Res 2011;29:1027-42. doi:10.1177/0734242X11406170. 
[20] Boldrin A, Neidel TL, Damgaard A, Bhander GS, Møller J, Christensen TH. Modelling of environmental impacts from biological treatment of organic municipal waste in EASEWASTE. Waste Manag 2011;31:619-30. doi:10.1016/j.wasman.2010.10.025.

[21] Levis JW, Barlaz MA. What is the most environmentally beneficial way to treat commercial food waste? Environ Sci Technol 2011;45:7438-44. doi:10.1021/es103556m.

[22] Berglund M, Börjesson P. Assessment of energy performance in the life-cycle of biogas production. Biomass Bioenergy 2006;30:254-66. doi:10.1016/j.biombioe.2005.11.011.

[23] Börjesson P, Tufvesson LM. Agricultural crop-based biofuels - resource efficiency and environmental performance including direct land use changes. J Clean Prod 2011;19:10820. doi:10.1016/j.jclepro.2010.01.001.

[24] Tarantini M, Buttol P, Maiorino L. An environmental LCA of alternative scenarios of urban sewage sludge treatment and disposal. Therm Sci 2007;11:153-64.

doi:10.2298/TSCI0703153T.

[25] Lederer J, Rechberger $\mathrm{H}$. Comparative goal-oriented assessment of conventional and alternative sewage sludge treatment options. Waste Manag 2010;30:1043-56. doi:10.1016/j.wasman.2010.02.025.

[26] Nakakubo T, Tokai A, Ohno K. Comparative assessment of technological systems for recycling sludge and food waste aimed at greenhouse gas emissions reduction and phosphorus recovery. J Clean Prod 2012;32:157-72. doi:10.1016/j.jclepro.2012.03.026.

[27] Amon T, Amon B, Kryvoruchko V, Machmüller A, Hopfner-Sixt K, Bodiroza V, et al. Methane production through anaerobic digestion of various energy crops grown in sustainable crop rotations. Bioresour Technol 2007;98:3204-12. doi:10.1016/j.biortech.2006.07.007.

[28] Gerin PA, Vliegen F, Jossart JM. Energy and CO2 balance of maize and grass as energy crops for anaerobic digestion. Bioresour Technol 2008;99:2620-7. doi:10.1016/j.biortech.2007.04.049.

[29] Jury C, Benetto E, Koster D, Schmitt B, Welfring J. Life Cycle Assessment of biogas production by monofermentation of energy crops and injection into the natural gas grid. Biomass Bioenergy 2010;34:54-66. doi:10.1016/j.biombioe.2009.09.011.

[30] Schumacher B, Oechsner $H$, Senn $T$, Jungbluth $T$. Life cycle assessment of the conversion of Zea mays and $x$ Triticosecale into biogas and bioethanol. Eng Life Sci 2010;10:577-84. doi:10.1002/elsc.201000069.

[31] Blengini G a., Brizio E, Cibrario M, Genon G. LCA of bioenergy chains in Piedmont (Italy): A case study to support public decision makers towards sustainability. Resour Conserv Recycl 2011;57:36-47. doi:10.1016/j.resconrec.2011.10.003. 
[32] Buratti C, Barbanera M, Fantozzi F. Assessment of GHG emissions of biomethane from energy cereal crops in Umbria, Italy. Appl Energy 2013;108:128-36.

doi:10.1016/j.apenergy.2013.03.011.

[33] González-García S, Bacenetti J, Negri M, Fiala M, Arroja L. Comparative environmental performance of three different annual energy crops for biogas production in Northern Italy. J Clean Prod 2013;43:71-83. doi:10.1016/j.jclepro.2012.12.017.

[34] Mafakheri F, Nasiri F. Modeling of biomass-to-energy supply chain operations: Applications, challenges and research directions. Energy Policy 2014;67:116-26.

doi:10.1016/j.enpol.2013.11.071.

[35] Walla C, Schneeberger W. The optimal size for biogas plants. Biomass Bioenergy 2008;32:551-7. doi:10.1016/j.biombioe.2007.11.009.

[36] Browne JD, Murphy JD. Assessment of the resource associated with biomethane from food waste. Appl Energy 2013;104:170-7. doi:10.1016/j.apenergy.2012.11.017.

[37] Gebrezgabher S a., Meuwissen MPM, Prins B a. M, Lansink AGJMO. Economic analysis of anaerobic digestion-A case of Green power biogas plant in The Netherlands. NJAS Wageningen J Life Sci 2010;57:109-15. doi:10.1016/j.njas.2009.07.006.

[38] Karellas S, Boukis I, Kontopoulos G. Development of an investment decision tool for biogas production from agricultural waste. Renew Sustain Energy Rev 2010;14:1273-82. doi:10.1016/j.rser.2009.12.002.

[39] Stürmer B, Schmid E, Eder MW. Impacts of biogas plant performance factors on total substrate costs. Biomass Bioenergy 2011;35:1552-60. doi:10.1016/j.biombioe.2010.12.030.

[40] Brown TR, Thilakaratne R, Brown RC, Hu G. Regional differences in the economic feasibility of advanced biorefineries: Fast pyrolysis and hydroprocessing. Energy Policy 2013;57:23443. doi:10.1016/j.enpol.2013.01.058.

[41] Delzeit R, Kellner U. The impact of plant size and location on profitability of biogas plants in Germany under consideration of processing digestates. Biomass Bioenergy 2013;52:43-53. doi:10.1016/j.biombioe.2013.02.029.

[42] Møller F, Martinsen L. Socio-economic evaluation of selected biogas. Aarhus University, DCE - Danish Centre for Environment and Energy, 231 pp. Scientific Report from DCE - Danish Centre for Environment and Energy No. 62, 2013. Last accessed June 2015 at <http://www.dmu.dk/Pub/SR62.pdf>.

[43] Riva C, Schievano a, D'Imporzano G, Adani F. Production costs and operative margins in electric energy generation from biogas. Full-scale case studies in Italy. Waste Manag 2014;34:1429-35. doi:10.1016/j.wasman.2014.04.018. 
[44] Schievano A, D'Imporzano G, Orzi V, Colombo G, Maggiore T, Adani F. Biogas from dedicated energy crops in Northern Italy: electric energy generation costs. GCB Bioenergy 2014:n/a - n/a. doi:10.1111/gcbb.12186.

[45] Murphy J., McKeogh E, Kiely G. Technical/economic/environmental analysis of biogas utilisation. Appl Energy 2004;77:407-27. doi:10.1016/j.apenergy.2003.07.005.

[46] Ayoub N, Martins R, Wang K, Seki H, Naka Y. Two levels decision system for efficient planning and implementation of bioenergy production. Energy Convers Manag 2007;48:709-23. doi:10.1016/j.enconman.2006.09.012.

[47] Ayoub N, Elmoshi E, Seki H, Naka Y. Evolutionary algorithms approach for integrated bioenergy supply chains optimization. Energy Convers Manag 2009;50:2944-55. doi:10.1016/j.enconman.2009.07.010.

[48] Luo L, van der Voet E, Huppes G. Biorefining of lignocellulosic feedstock--Technical, economic and environmental considerations. Bioresour Technol 2010;101:5023-32. doi:10.1016/j.biortech.2009.12.109.

[49] Santibañez-Aguilar JE, González-Campos JB, Ponce-Ortega JM, Serna-González M, ElHalwagi MM. Optimal Planning of a Biomass Conversion System Considering Economic and Environmental Aspects. Ind Eng Chem Res 2011;50:8558-70.

[50] Hennig C, Gawor M. Bioenergy production and use: Comparative analysis of the economic and environmental effects. Energy Convers Manag 2012;63:130-7. doi:10.1016/j.enconman.2012.03.031.

[51] Yabe N. Environmental and economic evaluations of centralized biogas plants running on cow manure in Hokkaido, Japan. Biomass Bioenergy 2013;49:143-51. doi:10.1016/j.biombioe.2012.12.001.

[52] Huijbregts T, Legrand G, Hoffmann C, Olsson R, Olsson Å. Long-term storage of sugar beet in North-West Europe. COBRI - Coordination Beet Research International. Report No.1, 2013. Last accessed June 2015 at <http://www.ifz-goettingen.de/media/downloads/16/cobri storage report 1-2013-standard.pdf>.

[53] Cencic O, Rechberger H. Material flow analysis with software STAN. J Environ Eng Manag 2008;18:3-7.

[54] Schoups G, Troch P a., Verhoest N. Soil moisture influences on the radar backscattering of sugar beet fields. Remote Sens Environ 1998;65:184-94. doi:10.1016/S00344257(98)00026-1.

[55] Thalbitzer F. Sukkeroer er fulde af gas. Planteavlerens Fagmagasin 2011:28-9. 
[56] APHA. Standard Methods for the Examination of Water and Wastewater. 21st ed. Washington, DC, US: American Public Health Association; 2005.

[57] GE Energy. Jenbacher type 4 - outputs and efficiencies. 2010. http://site.geenergy.com/prod_serv/products/recip_engines/en/type4.htm.

[58] Danish Energy Agency. Energy statistics 2012. Data, tables, statistics and maps 2014. Danish Energy Agency, 2014. Last accessed June 2015 at

<http://www.ens.dk/sites/ens.dk/files/dokumenter/publikationer/downloads/energy_stati stics_2012.pdf>

[59] Flesch TK, Desjardins RL, Worth D. Fugitive methane emissions from an agricultural biodigester. Biomass Bioenergy 2011;35:3927-35. doi:10.1016/j.biombioe.2011.06.009.

[60] Myhre G, Shindell D, Bréon F-M, Collins W, Fuglestvedt J, Huang J, et al. Anthropogenic and Natural Radiative Forcing. Clim Chang 2013 Phys Sci Basis Contrib Work Gr I to Fifth Assess Rep Intergov Panel Clim Chang Cambridge Univ Press Cambridge, United Kingdom New York, NY, USA 2013:659-740. doi:10.1017/ CBO9781107415324.018.

[61] Christensen TH, Gentil E, Boldrin A, Larsen AW, Weidema BP, Hauschild M. C balance, carbon dioxide emissions and global warming potentials in LCA-modelling of waste management systems. Waste Manag Res 2009;27:707-15. doi:10.1177/0734242X08096304.

[62] Ea Energianalyse. Anvendelse af biogas til el- og varmeproduktion. Analyser for Biogas Taskforce. Ea Energianalyse, Copenhagen, Denmark, 2014. Accessible at < http://www.ens.dk/sites/ens.dk/files/undergrund-forsyning/vedvarendeenergi/bioenergi/biogastaskforce/rapporter_taskforce/anvendelse_af_biogas_til_el_og_varme_2.pdf>

[63] Marañón E, Castrillón L, Quiroga G, Fernández-Nava Y, Gómez L, García MM. Co-digestion of cattle manure with food waste and sludge to increase biogas production. Waste Manag 2012;32:1821-5. doi:10.1016/j.wasman.2012.05.033.

[64] Schievano A, D'Imporzano G, Salati S, Adani F. On-field study of anaerobic digestion fullscale plants (part I): an on-field methodology to determine mass, carbon and nutrients balance. Bioresour Technol 2011;102:7737-44. doi:10.1016/j.biortech.2011.06.006.

[65] Liebetrau J, Reinelt T, Clemens J, Hafermann C, Friehe J, Weiland P. Analysis of greenhouse gas emissions from 10 biogas plants within the agricultural sector. Water Sci Technol 2013;67:1370-9. doi:10.2166/wst.2013.005.

[66] Yoshida H, Mønster J, Scheutz C. Plant-integrated measurement of greenhouse gas emissions from a municipal wastewater treatment plant. Water Res 2014;61:108-18. doi:10.1016/j.watres.2014.05.014. 
[67] Boldrin A, Astrup TF. GHG sustainability compliance of rapeseed-based biofuels produced in a Danish multi-output biorefinery system. Biomass Bioenergy 2015; 75:83-93.

[68] Stephenson a. L, von Blottnitz H, Brent a. C, Dennis JS, Scott S a. Global Warming Potential and Fossil-Energy Requirements of Biodiesel Production Scenarios in South Africa. Energy \& Fuels 2010;24:2489-99. doi:10.1021/ef100051g. 